\title{
Unexpected coral diversity on the breakwaters: potential refuges for depleting coral reefs
}

Received: 3 October 2006/ Accepted: 25 October 2006/ Published online: 24 November 2006

(C) Springer-Verlag 2006
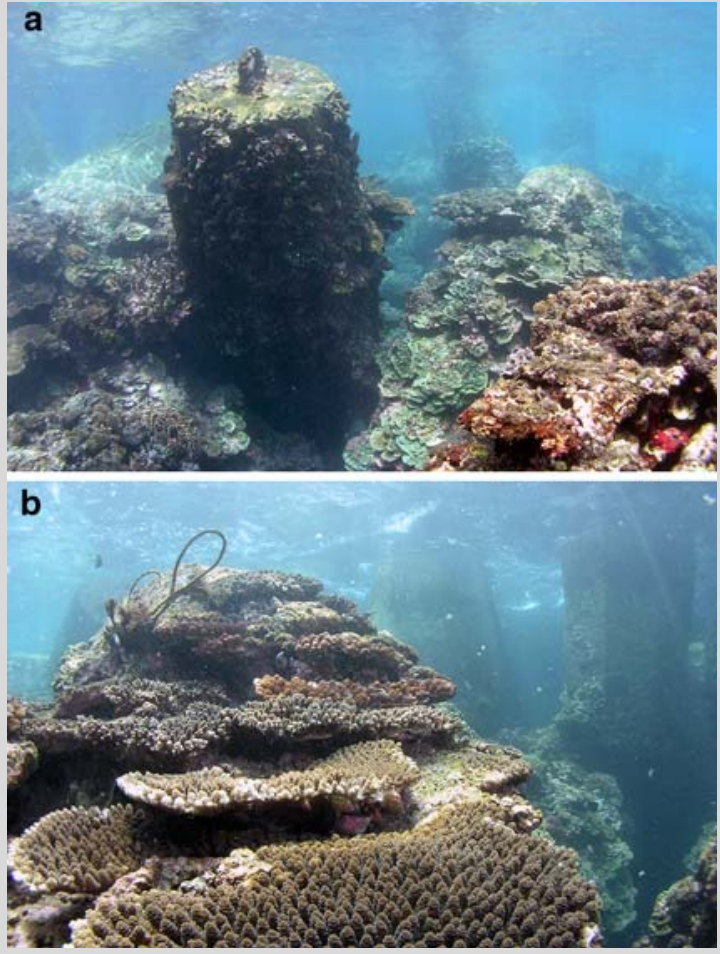

Fig. 1 a Coral communities on breakwaters at Dou-FuChia; b Acropora spp. abundance at depths of 1-3 m
Over $50 \%$ of the coastline in Taiwan has been protected by cement breakwaters in the last three decades. However, the breakwater's ability to prevent coastal erosion and its impact on the community structure of intertidal and subtidal biota remain controversial (Bulleri 2005). In July 2006, an evaluation of the current status of marine conservational areas, including several areas with breakwaters, was conducted along the coasts of Taiwan. Relatively high scleractinian coral diversity and cover was discovered at the breakwaters off Dou-Fu-Chia (DFC, $24^{\circ} 35^{\prime} 11^{\prime \prime} \mathrm{N}$ $\left.121^{\circ} 52^{\prime} 33^{\prime \prime} \mathrm{E}\right)$ in northeastern Taiwan and Yuan-An (YA, $22^{\circ} 48^{\prime} 35^{\prime \prime} \mathrm{N}$ $120^{\circ} 12^{\prime} 10^{\prime} \mathrm{E}$ ) in southeastern Taiwan (Fig. 1a). In total, 123 and 107 scleractinian species were recorded at DFC and YA, respectively. Video transect surveys along $200 \mathrm{~m}$ of the breakwaters revealed coral cover ranging from 25 to $40 \%$ at both DFC and YA with Acropora dominant at depths of 1-3 m (Fig. 1b).

The high coral diversity and cover at these breakwaters are unexpected, since both DFC and YA are surrounded by sandy bottoms and are distant $(>100 \mathrm{~km})$ from the major coral communities of southern Taiwan and the offshore islets which contain areas characterized as tropical coral reefs (Dai 1997). The coral communities in DFC and YA probably formed by the colonization of coral larval dispersing through currents from reefs around Taiwan (Chen 1999). Nevertheless, the reefs are under natural and anthropogenic stresses which are producing extensive losses of coral diversity, particularly Acropora corals (Chen and Dai 2004; Dai et al. 2004). Although they have been challenged for their negative role in coastal eco-technology, the breakwaters at DFC and YA may be playing a role as artificial 'refuges' during the course of depletion of coral reefs in Taiwan.

Acknowledgments Many thanks to Jay Yang and the Pacific Diving Centre for field assistance. The funding was supported by the Department of Fishery, Council of Agriculture, Executive Yuan and the Research Center for Biodiversity, Academia Sinica (RCBAS), Taiwan. This is the RCBAS Evolution and Ecology Group contribution no. 45.

References

Bulleri F (2005) Role of recruitment in causing differences between intertidal assemblages on seawalls and rocky shores. Mar Ecol Prog Ser 287:53-64

Chen CA (1999) Analysis of scleractinian distribution in Taiwan indicates a congruent pattern with sea surface temperature and currents: examples from Acropora and Faviidae corals. Zool Stud 38:119-129

Chen CA, Dai CF (2004) Local phase shift from Acropora-dominant to Condylactis-dominant community in the Tiao-Shi Reef, Kenting National Park, southern Taiwan. Coral Reefs 23:508

Dai CF (1997) Assessment of the present health of coral reefs in Taiwan. In: Grigg RW, Birkeland C (eds) Status of coral reefs in the Pacific. University of Hawaii, Honolulu, pp 123-131

Dai CF, Chen CH, Soong K, Chen CA, Hsieh HJ (2004) Report of ReefCheck in Taiwan. Council of Agriculture, Taipei, Taiwan (in Chinese)

K.-C. Wen · C.-M. Hsu · K.-S. Chen · M.-H. Liao · C.-P. Chen · C. A. Chen (ه)

Research Centre for Biodiversity, Academia Sinica, Taipei 11529, Taiwan

e-mail: cac@gate.sinica.edu.tw

C.-M. Hsu · M.-H. Liao · C. A. Chen

Institute of Oceanography, National Taiwan University, Taipei 10604, Taiwan

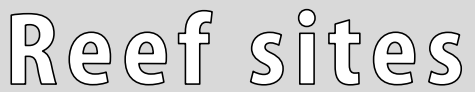

Coral Reefs (2007) 26:127

DOI $10.1007 / \mathrm{s} 00338-006-0177-7$ 